\title{
Atualidades/Actualities
}

\section{A FUNÇÃO SIMBÓLICA DOS MEDICAMENTOS}

Fernando Lefèvre:

LEFevre, F. A função simbólica dos medicamentos. Rev. Saúde públ., S. Paulo, $17: 500-3,1983$.

RESUMO: Foi analisada a função simbólica dos medicamentos como fazendo parte da exploração mercantil da saúde/doença, no Brasil. O medicamento, como mercadoria capaz de, numa sociedade imatura como a brasileira, encurtar a distância entre o concreto e o abstrato, entre o desejo e sua realização, necessita, para executar esta tarefa, que a saúde e a doença sejam reduzidas ao seu aspecto orgânico, com a omissão dos fatores causais de natureza social e comportamental. $O$ que torna a função simbólica dos medicamentos fato grave de Saúde Pública é que, em muitos casos, ela é eficaz. Assim sendo, todos os profissionais de saúde com responsabilidades educativas devem contribuir, nas suas atividades, para o amadurecimento da sociedade, procurando impedir que os medicamentos sejam usados para inibir a intervenção nos fatores sociais e comportamentais das doenças.

UNITERMOS: Medicamentos, consumo. Educação em saúde pública.

\section{INTRODUÇÃO}

Constitui um truismo afirmar-se que a saúde e a doença, em nosso pais, vem se constituindo, a cada dia que passa, em objeto de intensa exploração mercantil.

No contexto desta exploração, os medicamentos desempenham papel altamente relevante. Apenas a titulo de ilustração, vale assinalar que, no ano de 1981, o valor das vendas brutas de medicamentos, em nosso pais, foi de $\operatorname{Cr} \$ 171$ bilhões ${ }^{5}$.

Gostariamos de abordar aqui um aspecto pouco discutido, em relação ao tema dos medicamentos, que diz respeito à sua função significativa ou simbólica 1.4 .

O signo ou símbolo é um estímulo ou realidade material (seja ela um som, traços, gráficos, luzes, sombras, gesso talhado, ou certos tipos de mercadorias como automóveis de luxo, cachimbos, remédios e outras) que, através de um sistema convencional ou código, exerce a função de estar-no-lugar-de ou representar algo, sempre que o representado (pela sua natureza abstrata ou mistica, ou pelo fato de expressar mazelas ou contradiçōes sociais que não se deseja que apareçam à luz do dia, ou por qualquer outra razão impeditiva) não puder funcionar como representante de si mesmo.

Cordeiro² indica, em grandes linhas, o quadro geral, necessário para que se compreenda a função simbólica dos medicamentos, quando afirma: "... os medicamentos ocupam - lugar de símbolos e representações que obscurēcem os determinantes sociais das doenças, iludem os individuos com a aparência da eficácia científica e, comı mercadoria, realizam o valor e garantem a acumu-

Do Departamento de Prática de Saúde Pública da Faculdade de Saúde Pública da USP - Av.

Dr. Arnaldo. 715 - 01255 - São Paulo, SP - Brasil. 
LEFEVRE, F. A funçåo simbólica dos medica mentos. Rev. Saúde públ., S. Paulo, 17:500-3, 1983.

lação de um dos segmentos mais lucrativos do capital industrial".

Parece-nos necessário, no entanto, ir mais adiante, já que o detalhamento dos mecanismos intrínsecos próprios ao processo de significação ou simbolização, presente nos medicamentos, aumenta, segundo cremos, o valor de verdade da colocação genérica de Cordeiro, acima aludida.

\section{O organismo como "campo de jogo" da saúde-doença}

Nesse sentido, o primeiro ponto a assinalar diz respeito ao fato de ser a saúde, a nivel do senso comum, um valor altamente desejado e um conceito dotado de alto grau de abstração (daí as dificuldades de se definir saúde).

Duas questōes interligadas devem ser colocadas a este respeito:

a) Como aproximar os dris polos desta contradição?

b) Por que os setores hegemônicos da sociedade estão interessados na "promoção" e na "resolução" desta contradiçăo?

Antes de mais nada, busca-se resolver a referida contradição reforçando, através dos vários canais societários de comunicação de valores hegemônicos, a idéia de que a sede da saúde ou das ameaças à saúde, em outras palavras, o "campo de jogo", é o organismo humano.

Esta redução organicista é um primeiro passo, fundamental e imprescindivel para a resolução desta contradição, basicamente porque (e aí entra a resposta a segunda questão) através da redução organicista é possivel propor, como "solução" para a contradição, o consumo de mercadoria remédio.

Uma das caracteristicas, no plano da super-estrutura, de sociedades como a nossa, ou seja, formaçōes sociais historicamente jovens e que entraram precocemente no universo da produção capitalista moderna, é a da intensa promoção (basta ver a fantástica taxa de publicidade em nossos meios de comunicaçăo de massas) da idéia de que sempre é possivel, através do consumo de alguma mercadoria, encurtar ou mesmo eliminar a distância entre o concreto e o abstrato, entre o desejo e a sua realização (e não admitir esta distância, como sabemos, constitui um comportamento carracteristicamente infantil ou imaturo).

Assim, a saúde, para passar de desejo à realidade e, deste modo, gerar mercadorias (que são os instrumentos que operam esta passagem) precisa ser "biologizada".

A conseqüência disto é deixar no limbo (considerando, por exemplo, em termos de alocação de recursos, a Saúde Pública como uma atividade menor em relação à atenção curativa de saúde) as esferas "nebulosas" e "acadêmicas" do social, do comportamental, as verdadeiras sedes da saúde/ /doença, privilegiando como terreno de jogo o universo concreto e seguro do organismo e da biologia.

A escolha deste terreno de jogo não apenas possibilita a promoção da mercadoria remédio como uma mercadoria qualquer mas como uma mercadoria especial, porque lastreada pelo conhecimento científico, cujo valor de uso expressaria entăo a Verdade.

Em resumo, a função simbólica do medicamento pressupõe que a enfermidade seja considerada um fato orgânico, enfrentável através da mercadoria remédio, que é vista como o único modo cientificamente válido de se obter um valor altamęnte desejado (a saúde), no contexto de uma sociedade imatura.

\section{Eficácia do processo de simbolização}

Este processo de simbolização tem, usando-se termo da semiologia ${ }^{1}$ um referente, ou seja, uma base real, positiva (o que não é o caso de muitos simbolos, como por exemplo, os símbolos religiosos).

Com efeito, as doenças são "naturalmente" sentidas e experimentadas pelos indivíduos como estados orgânicos e o modo, igualmente "natural", de enfrenta- 
LEFivre, F. A funçăo simbólica dos medicamentos. Rev. saúàe públ, S. Paulo, 17:50C 1983.

mento social das doenças consiste na intervenção científica, rapidamente restabelecedora da normalidade, da Medicina e/ou dos medicamentos (no último caso via auto-medicação) : sobre o organismo.

E claro que, mutatis-mutandis, isto vale também para ações de Saúde Pública como as vacinações que, em última instância, são medicamentos.

A sociedade de consumo, ao mesmo tempo que promove, por todos os seus canais de comunicação, a idéia de que qualquer sofrimento, qualquer dor, qualquer estado, enfim, que fuja daquilo que ela institui como padrão, inclusive estético, constitui algo insuportável para o individuo; por outro lado, oferece a solução mágica, na ponta dos dedos: os comprimidos 4 .

Efetivamente, o problema central, do qual os sanitaristas e demais profissionais da Saúde devem estar muito conscientes, é que o medicamento consegue, muitas vezes, funcionar eficazmente como símbolo de saúde.

Quando Cordeiro ${ }^{2}$ diz que os medicamentos, "iludem os individuos com a aparência de eficácia científica" (o grifo é nosso) está afirmando uma verdade apenas parcial porque, de fato, os medicamentos estão conseguindo iludir ou estão funcionando como paliativos dos sofrimentos de massas enormes de individuos, não com a aparência mas com a realidade da sua eficácia cientifica. $O$ grave do mito dos medicamentos é que, de fato, "a dor some com. .".

\section{CONCLUSOES}

O medicamento, em nosso pais, está funcionando (e eficazmente) como símbolo de saúde, ou seja, como realidade matet que, sob a forma de um produto existe (e, perfeitamente acessivel ao consumic comum) num mercado de oferta e procı de bens e serviços de saúde, está ocupar - lugar da Saúde já que ela não está cr seguindo aparecer como representante si mesma porque:

a) para que isto ocorresse seria necessá ir às causas sociais e comportament da doença, o que, pelo fato de implic necessariamente, resultados a lon prazo, choca fortemente com a visào doença como um estado orgân altamente indesejável que deve, con qüentemente, ser o mais rapidame possivel aliviado ou superado;

b) ir às causas comportamentais ( doenças implica, quase sempre, dc rosas ou trabalhosas mudanças de 1 bitos ou comportamentos ou proc sos terapêuticos longos, custosos e certos como as psicoterapias ou psi nálises;

c) remontar as causas sociais das doen não interessa às forças que, dentro fora do atual sistema de saúde, se be ficiariam do estado de coisas sanitát educativo e sócio-econômico vigente nosso país.

Cabe a todos os profissionais que, dir ou indiretamente, têm, nas suas ações saúde, responsabilidades educativas, rever esta situação, enfrentando as barreiı enunciadas acima, contribuindo no senti de tornar mais madura nossa sociedade, $r$ permitindo que os medicamentos ocupem indevido lugar de substitutivos ou simbo de saúde, cuja função consistiria em ini a intervenção nas causas sociais e compr tamentais das doenças. 
LEFEVRE, F. A função simbolica dos medicamentos. Rev. Saúde públ., S. Paulo, 17:500-3, 1983.

LEFEVRE, F. [The symbolic function of drugs]. Rev. Saúde públ., S. Paulo, 17: 500-3, 1983.

ABSTRACT: The symbolic function drugs as part of the commercial exploitation of health/disease in Brazil is analysed. In an immature society like the Brazilian one, the drug-in so far as it performs the role of a product able to shorten the distance between the concrete and the abstract, between the desire and its fulfilment - needs, in order to accomplish this task, that health and disease of reduced to their purely organic features, and ignores those causal factors of a social and behavioral nature. What makes the symbolic function of drugs a rather serious public health factor is that, in many cases, it is effective. Thus all health professionals with educational responsibilities should contribute, through their activities, to the creation of social maturity, in the attempt to prevent drugs being used in such a way as to inhibit action against the social and behavioral causes of diseases.

UNITERMS: Drug consumption. Health education.

\section{REFERENCIAS BIBLIOGRAFICAS}

1. BUYSSENS, E. Semiologia e comunicacão lingǘstica. Sáo Paulo, Cultrix, 1972.

2. CORDEIRO, H, A indústría da saúde no Brasil. Rio de Janeiro, Graal/Cebes, 1980.

3. HAFEN, B.Q. \& PETERSON, B. Medicines and drugs. Philadelphia, Lea and Febiger, 1978.
4. PIERCE, C.S. Semítica e filosofia. São Paulo, Cultrix, 1975.

5. SECRETARIA DA INDUSTRIA E COMERCIO DA BAHIA, Indústria farmaceutica no Brasil: procedimentos essenciais. Salvador, BA, 1983.

Recebido para publicação em 01/0r/1983

Aprovado para publicacão em 01/09/1983 